\title{
BMJ Open Impact of donor with evidence of bacterial infections on deceased donor liver transplantation: a retrospective observational cohort study in Taiwan
}

\author{
Kun-Ming Chan, ${ }^{\odot}$ Chih-Hsien Cheng, Tsung-Han Wu, Chen-Fang Lee, \\ Ting-Jung Wu, Hong-Shiue Chou, Wei-Chen Lee
}

To cite: Chan K-M, Cheng C-H, Wu T-H, et al. Impact of donor with evidence of bacterial infections on deceased donor liver transplantation: a retrospective observational cohort study in Taiwan. BMJ Open 2019;9:e023908. doi:10.1136/ bmjopen-2018-023908

- Prepublication history and additional material for this paper are available online. To view these files, please visit the journal online (http://dx.doi org/10.1136/bmjopen-2018023908).

Received 2 May 2018 Revised 5 0ctober 2018 Accepted 25 January 2019

Check for updates

(C) Author(s) (or their employer(s)) 2019. Re-use permitted under CC BY-NC. No commercial re-use. See rights and permissions. Published by BMJ.

Department of General Surgery, Chang Gung Memorial Hospital Linkou Branch, Taoyuan city, Taiwan

Correspondence to Dr Kun-Ming Chan; chankunming@adm.cgmh. org.tw

\section{ABSTRACT}

Objective The shortage of available donor organs is an unsolvable concern leading to an expansion in the donor criteria for organ transplantation. Here, we describe our experience and assess the outcomes in recipients who obtained a graft from a donor with bacterial infections in deceased donor liver transplantation (DDLT).

Methods All DDLTs between January 1991 and February 2017 were retrospectively reviewed. Patients were categorised into two groups based on the recipients who obtained a graft from a donor with (group I) or without (group II) evidence of bacterial infections. Outcomes and bacterial infections were compared between the two groups of recipients.

Results Overall, a total of 285 DDLTs were performed from 248 donors consisting of 48 split liver grafts and 208 whole liver grafts. Of those, 98 recipients (group I, $34.3 \%$ ) were transplanted with a graft from 78 donors with positive bacterial cultures. Donor sputum cultures had the highest rate of positive bacterial growth, accounting for $26.6 \%$ of donors. Overall survival (OS) was not significantly different between the two groups $(p=0.9746)$. The 0 S rates at 1 and 3 years were $73.5 \%$ and $69.2 \%$, respectively, in the group I recipients versus $68.8 \%$ and $62.4 \%$ in the group II recipients. Importantly, no hospital mortality was related to donor-derived bacterial infections.

Conclusion Transmission of bacteria from the donor to the recipient is infrequent in DDLT. Therefore, potential donors with positive bacterial infections should not be excluded for organ transplantation to increase organ availability and ameliorate the organ shortage.

\section{INTRODUCTION}

Organ transplantation is a promising alternative for the treatment of many end-stage diseases. However, the discrepancy between organ demand and donor availability is currently an unsolvable concern. Therefore, expanded donor criteria including older donors, circulatory death donors or donors with mild diseases and henceforth are increasingly used as donors for organ transplantation. Subsequently, there is a high possibility of the transmission of unwanted infectious

\section{Strengths and limitations of this study}

- The shortage of deceased organ donors is stringent in Oriental countries as compared with Western countries, and thus every donor should be carefully judged for organ transplantation to achieve greatest effectiveness.

- This study enrolled 285 deceased donor liver transplantation in the setting of scarce organ donation and analysed the influence of donors with evidence of bacterial infections on liver transplantation.

- The results show that the incidence of donor-transmitted bacterial infections was very low, suggesting that donors with a bacterial infection should not be excluded as organ donors for liver transplantation.

- The study is limited by its retrospective entity in a single transplantation centre with some patients.

diseases following organ donation. Infectious microbes including viruses, bacteria, parasites and fungi that are present in organ donors have the potential to be transmitted to the transplant recipient. ${ }^{1-3}$ The influence of these donor-transmitted infectious diseases on the outcome of organs transplantation could be immediately after transplantation or lasting several years afterward. However, the study focuses on assessing donor with bacterial infection and related impact immediately after liver transplantation.

Any active bacterial infection in the donor may result in a lethal complication immediately after transplantation if bacteria are transmitted to the recipient during organ transplantation. Thus, the majority of transplantation surgeons are reluctant to transplant organs known to be infected by active bacteria. Specifically, the shortage of deceased donor is very stringent particularly in Oriental countries. In this study, donors with bacterial infections were analysed to assess the influence of an infected donor 

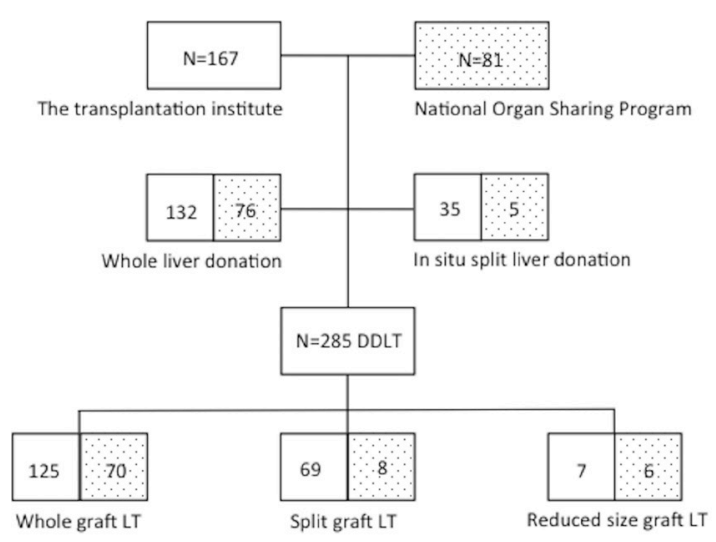

Figure 1 Flow diagram of organ donors and liver transplantations assessed in this study. DDLT, deceased donor liver transplantation; LT, liver transplantation.

on the outcome of deceased donor liver transplantation (DDLT). These results might provide additional information for the selection of deceased donors for liver transplantation (LT).

\section{METHODS \\ Patients}

A total of 285 consecutive DDLTs were performed during the period between January 1991 and February 2017 at the Transplantation Institute. All medical records of donors and recipients were retrospectively reviewed. Of all LT, liver grafts were procured from 248 donors including 81 donors from the national organ sharing programme and 167 donations from the institute. No executed prisoner organs were used in this study. Liver graft donations and transplantations are illustrated in figure 1. Overall, 40 donors underwent split liver donation, and whole liver grafts were procured from the 208 donors. Among whole liver donors, 13 donors had reduced-size liver grafts from a partial liver resected ex vivo to be implanted in recipients with a relatively small abdominal cavity.

\section{Donor survey}

All potential donors were thoroughly checked by laboratory tests for hepatitis B and C virus, HIV, cytomegalovirus, Epstein-Barr virus, toxoplasmosis and syphilis. Generally, chest radiography and ultrasonography of the heart, liver and kidney would be routinely performed prior to the donation of solid organs. With regard to the assessment of bacterial infection, serial samples including bronchial aspirates, urine and blood were obtained for culture before organs donation.

Generally, the potential donor should be haemodynamic stable with acceptable cardiopulmonary function, absence of sepsis or uncontrollable bacterial infection and without malignant neoplasm contraindicated for donation. Donor with virus including hepatitis B, C virus and HIV (after November 2016) were not contraindicated for organs donation, but could be transplanted to a recipient with same viral status. For liver donation, the liver functional reserve of donor should be acceptable and less than $50 \%$ of hepatic parenchyma with steatosis. If the donor was eligible for organ donation, transplantation surgeons would proceed to organ procurement after the determination of brain death by specialists. There are no organs obtained from non-heart beating donor in this study.

The decision to perform split liver grafts in two adult recipients was based on preoperative hepatic sonography and an intraoperative assessment of the liver graft. Transection of the hepatic parenchyma for split liver grafts was all performed in situ as previously described. ${ }^{4}$ Importantly, bile was routinely obtained through the common bile duct for bacterial culture before flushing the biliary tree during liver graft procurement from all donors.

\section{Liver transplantation recipients}

All graft implantations were performed using standard techniques without venovenous bypass. Generally, prophylactic antibiotics were usually administered for all recipients after transplantation unless the susceptibility profile required specific antibiotics prior to transplantation. The selection of prophylactic antibiotics was based on the illness of recipients, in which third-generation cephalosporins was given to recipients with Model For End-Stage Liver Disease (MELD) scores less than 20; a combination of vancomycin and imipenem/cilastatin was administered to recipients with MELD scores above 20. In addition, antibiotic treatment specific to the recognised micro-organisms from donor was also administered after transplantation based on the result of donor's bacterial culture. The use of antifungal prophylaxis was optional for recipients who had a high risk of fungal infections such as longer hospitalisation before transplantation, longer operation time, massive blood loss and blood transfusion during the operation. The immunosuppressive regimen for recipients after transplantation mainly consisted of a combination of methylprednisolone, tacrolimus and mycophenolate mofetil and adjusted based on the clinical assessment of the recipient.

\section{Outcomes and statistical analysis}

Recipients were categorised into two groups: group I consisted of recipients transplanted with a graft procured from a donor with a positive bacterial culture, and group II included recipients who obtained a graft from a donor without evidence of bacterial infection. Bacterial infection was intensively monitored using samples from the blood, drainage tubes and catheters for all recipients after LT. Micro-organisms that grew in all cultures within 30 days after LT were recorded and assessed for bacterial infection transmission from donor. The recipient's outcome measure was the overall survival (OS), which was calculated from the date of LT to the date of death or the end of this study. Survival curves were constructed by the Kaplan-Meier method and further compared by the log-rank test. All variables were assessed for multivariate analyses using the Cox hazards regression model. 


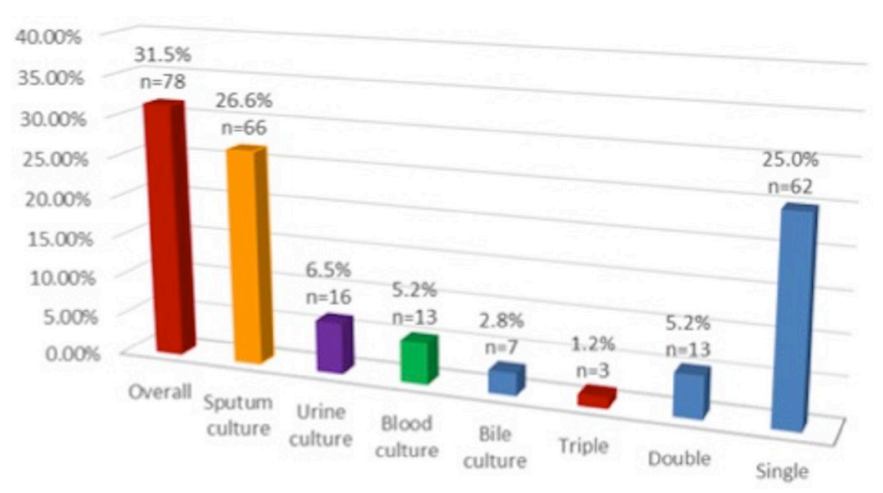

Figure 2 The rate of positive bacterial cultures in donors.

Comparison of continuous variables were performed by Student's t-test, and categorical variables were compared by the $\mathrm{X}^{2}$ or Fisher's exact test as appropriate. All data were analysed using the statistical software SPSS V.20.0 for Windows. A p-value of $<0.05$ was defined as statistically significant.

\section{Patient and public involvement statement}

This study analysed a retrospective data review. There was no patient or public involvement in this study including in the design, recruitment and conduct of the study.

\section{RESULTS}

\section{Donor features}

All donors were donating after brain death; the 248 donors consisted of 174 males and 74 females. The median age of the donors was 40 years old and ranged from 9 to 75 years old. The major causes of brain death were cerebrovascular accidents in 137 donors $(55.2 \%)$ and head injury in 48 donors $(19.4 \%)$. The median duration of stay in the intensive care unit before donation was 3 days (ranging from 1 to 95 days). Overall, 78 donors $(31.5 \%)$ had positive bacterial culture samples, in which $3(1.2 \%)$ of them had triple site positives, $13(5.2 \%)$ had double site positives and $62(25 \%)$ had only a single site positive (figure 2). Most positive bacterial cultures were from bronchial aspirates of sputum, which were noted in 66 donors that accounted for $26.6 \%$ of all donors and $84.6 \%$ among donors with positive bacterial infections. In addition, bacterial growth was detected from blood cultures in 13 donors $(5.2 \%)$, from urine cultures in 16 donors $(6.5 \%)$ and from bile cultures in 7 donors $(2.8 \%)$.

\section{Micro-organisms in donor cultures}

All positive bacterial cultures derived from donors are described in table 1 . A total of 21 bacterial species were identified, including 9 Gram-positive, 11 Gram-negative and 1 Gram-variable. Among these, the three most common bacteria were Klebsiella pneumoniae $(\mathrm{n}=34)$, Staphylococcus aureus $(\mathrm{n}=32)$ and Escherichia coli $(\mathrm{n}=13)$. Coagulase-negative Staphylococcus was the first-ranked bacterium found in the blood cultures of seven donors, and E. coli was the most common bacterium found in the urine cultures of eight donors. K. pneumoniae was isolated from 32 donor sputum cultures and 2 donor bile cultures. In addition, Pseudomonas aeruginosa, a relative common nosocomial species, was cultivated from 10 donor sputum cultures.

\section{Recipient outcomes}

Among the 285 DDLTs, 98 recipients (group I) obtained grafts from 78 donors with positive bacterial cultures, while the remaining 187 recipients (group II) were transplanted with grafts from 170 donors who had no evidence of bacterial infection. The clinical characteristics of recipients are summarised and compared in table 2 . The majority of clinical features were similar between the two groups. However, the mean recipient age in group I was significantly greater than that of group II recipients $(p=0.002)$, and a significantly higher ratio of group II recipients received whole liver grafts for transplantation ( $p=0.0002)$. Moreover, group I patients had relatively higher ratio of comorbidity as compared with group II patients at the time of transplantation $(\mathrm{p}=0.0414)$. Importantly, the rates of bacterial growth from blood cultures and hospital mortality within 30 days after LT were not significantly different between the two groups. Overall, $159(55.8 \%)$ patients were still alive by the end of the study, including $57(58.2 \%)$ patients in group I and 102 $(54.5 \%)$ patients in group II.

In group I, only one recipient (1.02\%) had Acinetobacter baumannii detected in a blood culture after LT, which was the same bacterium cultured from the donor's sputum prior to organ donation. The recipient was indicated for LT due to hepatitis B virus-related end stage liver cirrhosis and obtained a right liver graft from a split liver donation. However, no evidence of A. baumannii growth was noted in the blood culture in the other recipient who received a left liver graft from the same donor. Patients who obtained grafts from donor with and without bacterial infection were compared, and similar outcomes were found between the two groups (figure $3, \mathrm{p}=0.9746$ ). The analysis of the survival curves showed that the OS rates at 1 and 3 years were $73.5 \%$ and $69.2 \%$, respectively, in group I recipients, while the corresponding values were $68.8 \%$ and $62.4 \%$ in group II recipients. The HR of donor with evidence of bacterial infection was $1.01 \quad(p=0.956$, $95 \%$ CI 0.69 to 1.47 ) for OS after transplantation, and the adjusted HR were $0.80(\mathrm{p}=0.310,95 \%$ CI 0.52 to 1.23$)$ after adjusted for gender, age and comorbidity.

In addition, a propensity score matching was performed to minimise the influence of confounding factors between the two groups. According to the matching analysis, there were also no significant differences between the two groups in terms of OS (figure 4, $\mathrm{p}=0.3443$ ). The 1- and 3-year-OS was $73.5 \%$ and $62.2 \%$, respectively, for patients in group I, and $69.2 \%$ and $56.1 \%$, respectively, for patients in group II. Moreover, multivariate regression analysis showed that the presence of donor with bacterial infection was not a significant prognostic factor affecting 
Table 1 Micro-organisms cultured from donors

\begin{tabular}{|c|c|c|c|c|c|}
\hline \multirow[b]{2}{*}{ Microorganisms } & \multicolumn{4}{|c|}{ Bacterial cultures } & \multirow[b]{2}{*}{ Total } \\
\hline & Sputum & Urine & Blood & Bile & \\
\hline \multicolumn{6}{|l|}{ Gram-positive bacteria } \\
\hline Staphylococcus aureus & 31 & - & 1 & - & 32 \\
\hline $\begin{array}{l}\text { Coagulase-negative } \\
\text { Staphylococcus }\end{array}$ & - & - & 7 & 1 & 8 \\
\hline Enterococcus faecalis & - & 5 & 1 & - & 6 \\
\hline Staphylococcus & 1 & - & 2 & - & 3 \\
\hline Streptococcus pneumoniae & 3 & - & - & - & 3 \\
\hline Staphylococcus epidermidis & - & 1 & 1 & - & 2 \\
\hline Aerococcus & - & - & - & 1 & 1 \\
\hline Enterococcus faecium & - & - & - & 1 & 1 \\
\hline Propionibacterium acnes & - & - & - & 1 & 1 \\
\hline \multicolumn{6}{|l|}{ Gram-negative bacteria } \\
\hline Klebsiella pneumoniae & 32 & - & - & 2 & 34 \\
\hline Escherichia coli & 4 & 8 & - & 1 & 13 \\
\hline Pseudomonas aeruginosa & 10 & 2 & - & - & 12 \\
\hline Haemophilus influenzae & 8 & - & - & - & 8 \\
\hline Enterobacter cloacae & 4 & 3 & - & - & 7 \\
\hline Acinetobacter baumannii & 5 & - & 1 & - & 6 \\
\hline Stenotrophomonas maltophilia & 2 & 2 & 1 & 1 & 6 \\
\hline Enterobacter aerogenes & 4 & - & 1 & - & 5 \\
\hline Veillonella sp & - & - & 2 & - & 2 \\
\hline Proteus mirabilis & 2 & - & - & - & 2 \\
\hline Serratia marcescens & 2 & - & - & - & 2 \\
\hline \multicolumn{6}{|l|}{ Other } \\
\hline Gardnerella vaginalis & - & 1 & - & - & 1 \\
\hline
\end{tabular}

Number represents number of patients.

recipient's outcome after liver transplantation as well (online supplemental table 1).

\section{DISCUSSION}

Although LT is currently considered the definitive treatment for individuals with end-stage liver disease, unexpected transmission of infections from the donor to the recipient remains a major concern. Although rare, complication related to donor-derived infectious disease is associated with significant morbidity and mortality. ${ }^{35-7}$ Among the types of donor-derived infections, bacterial transmission from the donor could result in bacteraemia immediately after transplantation and lead to lethal complications. However, deceased donors are extremely rare in Oriental countries, and the organ shortage for LT is exceptionally large as compared with Western countries. ${ }^{89}$ Therefore, every donor should be carefully judged for organ transplantation. This study analysed donors in terms of bacterial infections in the setting of scarce organ donation. The results show that the incidence of donor-transmitted bacterial infections was very low, suggesting that donors with a bacterial infection should not be excluded as organ donors for LT.

Generally, bacteria are the most common cause of infections in LT recipients. However, opportunistic infections are generally uncommon in the first 1-4 weeks after transplantation, depending on the recipient's net state of immunity. Thus, unexplained early infections in this period are generally associated with surgery-related complications or donor-derived infections. This study examined all recipient blood cultures for bacteria within 30 days after LT to match the donor's bacterial infection. In line with previous reports, the incidence of possible bacterial transmission from the donor was very low. ${ }^{10} 11$ Only one recipient's blood culture had the same bacterium as the donor, and accounted for only $1.02 \%$ of all recipients in the current study.

A. baumannii is a typical Gram-negative bacterium that can be an opportunistic pathogen affecting patients with compromised immune systems. ${ }^{1213}$ However, the recipient 
Table 2 Clinical characteristics of patients with deceased donor liver transplantation

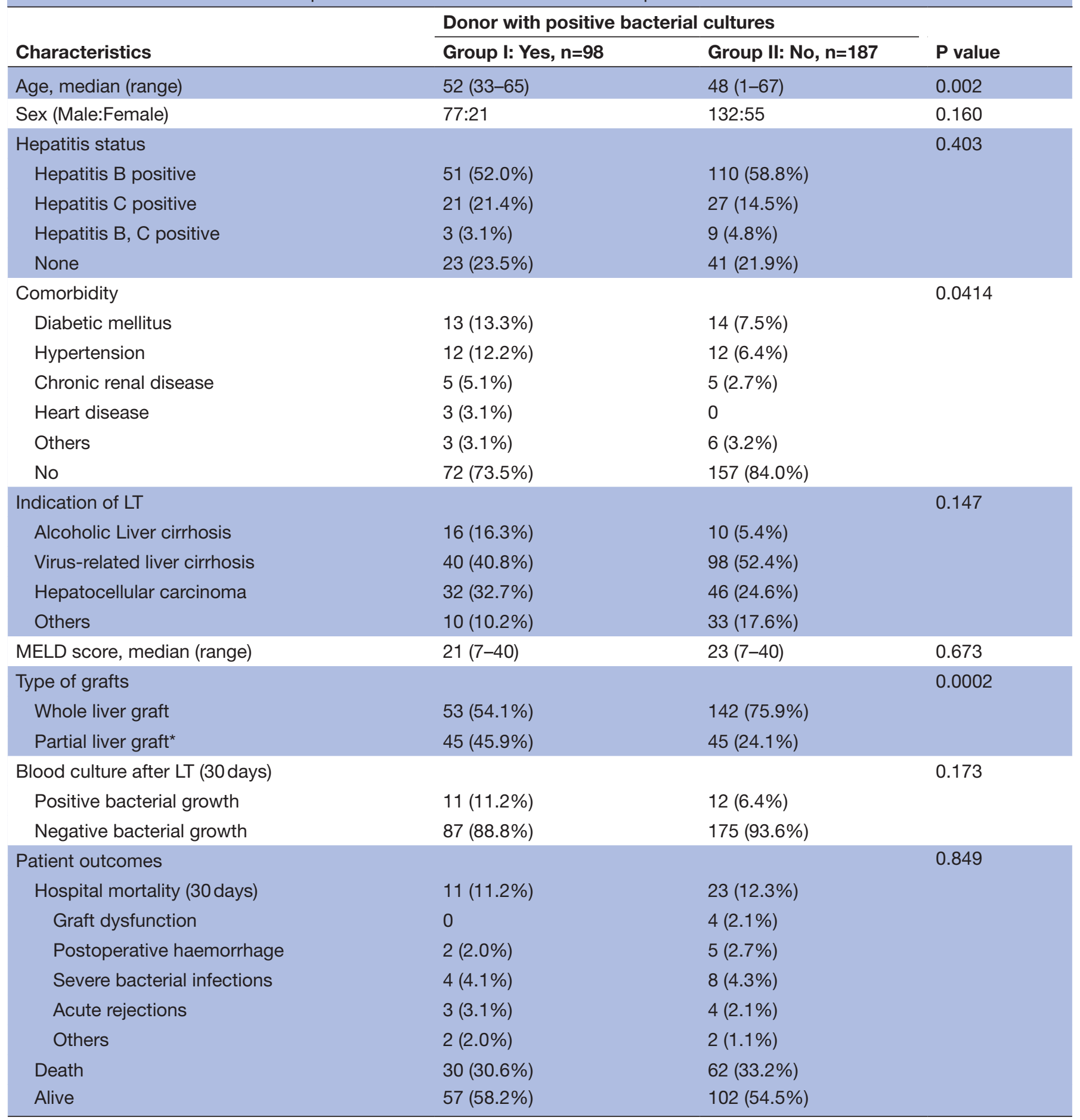

*Partial liver grafts included split liver and reduced-size liver grafts.

LT, liver transplantation; MELD, Model for End-stage Liver Disease.

who obtained the left liver graft from the same donor had no evidence of this bacterium in their blood cultures after LT. Therefore, the recipient's pathogen could be a hospital-derived nosocomial infection instead of transmission from donor. Meanwhile, liver grafts are usually flushed with organ preserving solution during organ procurement, and re-perfused with more than $1500 \mathrm{~mL} / \mathrm{min}$ of the recipient's blood after graft implantation. As such, bacteria within the liver graft are likely to be diluted by these process, and the chance of donor-derived bacterial infection in the recipient is very low.

However, the possibility of potential donor with severe bacterial infections such as A. baumannii, vancomycin resistance $E$. coli or multidrug-resistant bacteria might be existed. These antimicrobial resistance bacteria were mostly detected in patients with severe illness or 


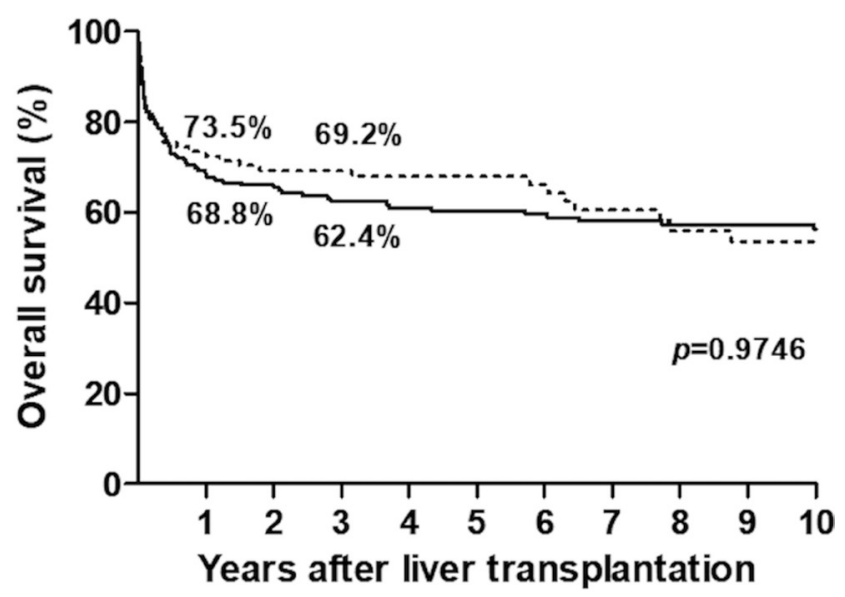

No. at risk

$\begin{array}{llllllllllll}\text { Group I } & 98 & 72 & 60 & 58 & 51 & 42 & 37 & 32 & 24 & 23 & 20\end{array}$ $\begin{array}{llllllllllll}\text { Group II } & 187 & 128 & 111 & 98 & 88 & 84 & 80 & 77 & 73 & 72 & 64\end{array}$

Figure 3 Comparison of cumulative overall survival (OS) for the patients shows no significant difference between the two groups. Kaplan-Meier OS curves of patients $(p=0.9746)$ group I (...), group II (-).

compromised immune systems, and thus they might be unacceptable for organ donation because of poor general condition. Although the usage of organs from donors infected with drug-resistance bacteria remains uncertain, the urgent demand for organs perhaps would lead to the use of organs from these donors for specific recipients based on the urgency of the need for transplantation. Nonetheless, the study was limited by its small number of patients, in which the impact of the drug-resistance bacteria on the outcome of DDLT could not be truly reflected. Therefore, further information from a larger cohort study to clarify the influence of drug-resistance bacteria on organs transplantation is required in the future.

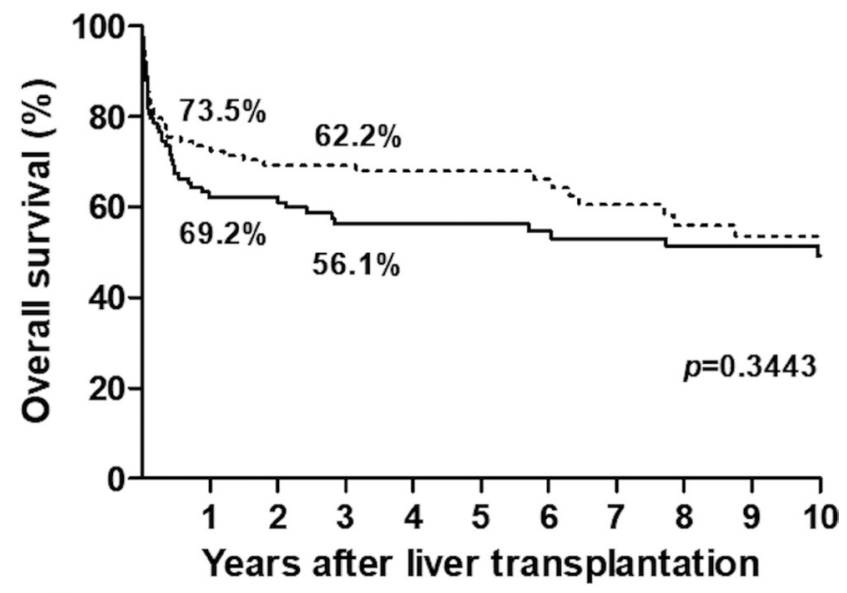

No. at risk

$\begin{array}{llllllllllll}\text { Group I } & 98 & 72 & 60 & 58 & 49 & 42 & 37 & 32 & 24 & 23 & 20\end{array}$ $\begin{array}{llllllllllll}\text { Group II } & 98 & 63 & 54 & 45 & 40 & 38 & 36 & 35 & 31 & 30 & 23\end{array}$

Figure 4 Comparison of cumulative overall survival (OS) for the patients shows no significant difference between the two groups. Kaplan-Meier OS curves of patients after propensity score matching $(p=0.3443)$ group I $(\ldots)$, group II $(-)$.
Our data are similar to previous reports showing that the highest positive rate of bacterial culture of the donor was from sputum cultures. ${ }^{11} 14$ The most common pathogens cultivated from bronchial aspirates of the donors in this study were $K$. pneumoniae and S. aureus. Both pathogens are members of the normal flora of the body and are frequently found in the respiratory tract and skin. ${ }^{15} 16$ Klebsiella infections are mostly seen in people with a weakened immune system or a nosocomial infection, and $S$. aureus is not always pathogenic. In addition, E. coli was the most common pathogen found in the urine cultures of our donor, which might be related to either translocation from the gastrointestinal tract or contamination with faeces. Therefore, culture results from donors that show these pathogens could be ignored so that the donors are not excluded from organ donation.

Importantly, each potential donor should be comprehensively screened for medical conditions that may affect the recipient, which might include the presence of transmissible disease, malignancies or any other known condition that may be transmitted by the donor organ. However, it is currently impossible to screen potential donors for all potential pathogens during the narrow timeframe of the organ donation process. Specifically, bacterial cultures of potential donors take time and may not provide results prior to organ procurement for transplantation. Likewise, a donor may have a bacterial infection that has been appropriately treated. Under such circumstances, treatment of the recipient for the recognised infection immediately after transplantation might be satisfactory.

The preventive strategy of universal prophylaxis mainly relied on the clinical status of the recipient. Generally, micro-organisms transmitted from donors is not likely to cause infectious complications in every recipient, and the risk of infection is mostly associated with the patient's net state of immunity. Therefore, antimicrobial prophylaxis should be adjusted based on the severity of recipient's illness, individual exposures and hospital epidemiology. In addition, antimicrobial prophylaxis should also be adjusted according to identified micro-organisms from donors. As a result, it can provide adequate coverage of bacterial infections cultured from donor and prevent infectious complication related to transmission of donor-derived infectious diseases.

\section{CONCLUSIONS}

Although the study is limited by its retrospective entity in a single transplantation centre with a small number of patients, several marked observation might be helpful in clinical practice. In addition, available organ donor numbers lag behind current and future needs, and this organ shortage has thus forced clinicians to expand the donor pool by using donors with the risk of transmitting infectious diseases. The annual deceased organ donation rate has recently increased to 12.3 per million population in Taiwan, but the number of DDLTs is still not satisfactory, with an average of 100 cases per year. ${ }^{17}$ 
Many other counties may also encounter this situation regarding deceased donor organ transplantation and LT. As a result, a bacterial infection in the donor should not preclude the use of organs for transplantation. Moreover, the possibility of bacterial transmission from the donor seems to be extremely low considering fluid dilution and the non-specific culture results.

Contributors Study concept, design and drafting the manuscript: K-MC. Acquisition of data: K-MC, T-HW, C-HC, C-FL, T-JW, H-SC and W-CL. Critical revision of the manuscript for important intellectual content: $\mathrm{K}-\mathrm{MC}$ and $\mathrm{W}-\mathrm{CL}$.

Funding The authors have not declared a specific grant for this research from any funding agency in the public, commercial or not-for-profit sectors.

Competing interests None declared.

Patient consent for publication Not required.

Ethics approval The Institutional Review Board of Chang Gung Memorial Hospital (Approval No.: 98-3794B).

Provenance and peer review Not commissioned; externally peer reviewed.

Data sharing statement № additional data available.

Open access This is an open access article distributed in accordance with the Creative Commons Attribution Non Commercial (CC BY-NC 4.0) license, which permits others to distribute, remix, adapt, build upon this work non-commercially, and license their derivative works on different terms, provided the original work is properly cited, appropriate credit is given, any changes made indicated, and the use is non-commercial. See: http://creativecommons.org/licenses/by-nc/4.0/.

\section{REFERENCES}

1. Fishman JA. Infection in solid-organ transplant recipients. $N$ Engl $J$ Med 2007;357:2601-14.
2. Fishman JA. Infection in organ transplantation. Am J Transplant 2017:17:856-79.

3. Ison MG, Grossi P. Donor-derived infections in solid organ transplantation. Am J Transplant 2013;13:22-30.

4. Lee WC, Chan KM, Chou HS, et al. Feasibility of split liver transplantation for 2 adults in the model of end-stage liver disease era. Ann Surg 2013;258:306-11.

5. Ison MG, Nalesnik MA. An update on donor-derived disease transmission in organ transplantation. Am J Transplant 2011:11:1123-30.

6. Cerutti E, Stratta C, Romagnoli R, et al. Bacterial- and fungal-positive cultures in organ donors: clinical impact in liver transplantation. Liver Transp/ 2006;12:1253-9.

7. Lumbreras C, Sanz F, González A, et al. Clinical significance of donor-unrecognized bacteremia in the outcome of solid-organ transplant recipients. Clin Infect Dis 2001;33:722-6.

8. Lo CM. Deceased donation in Asia: challenges and opportunities. Liver Transp/ 2012;18:S5-7.

9. Wang TH, Lee PC, Chiang YJ. Taiwan's organ donation and transplantation: observation from national registry point of view. $J$ Formos Med Assoc 2017;116:649-51.

10. Outerelo C, Gouveia R, Mateus A, et al. Infected donors in renal transplantation: expanding the donor pool. Transplant Proc 2013;45:1054-6.

11. Yuan $X$, Chen $C$, Zhou J, et al. Organ donation and transplantation from donors with systemic infection: a single-center experience. Transplant Proc 2016;48:2454-7.

12. Antunes LC, Visca P, Towner KJ. Acinetobacter baumannii: evolution of a global pathogen. Pathog Dis 2014;71:292-301.

13. Yeom J, Shin JH, Yang JY, et al. (1)H NMR-based metabolite profiling of planktonic and biofilm cells in Acinetobacter baumannii 1656-2. PLoS One 2013;8:e57730.

14. Paredes D, Gambra MP, Cervera C, et al. Characterization of the organ donor with bacteremia. Transplant Proc 2007;39:2083-5.

15. Kluytmans $\mathrm{J}$, van Belkum $\mathrm{A}$, Verbrugh $\mathrm{H}$. Nasal carriage of Staphylococcus aureus: epidemiology, underlying mechanisms, and associated risks. Clin Microbiol Rev 1997;10:505-20.

16. Podschun R, Ullmann U. Klebsiella spp. as nosocomial pathogens: epidemiology, taxonomy, typing methods, and pathogenicity factors. Clin Microbiol Rev 1998;11:589-603.

17. Wang TH, Chang YP, Chiang WL. Improving donation rates in Taiwan. Transplantation 2016;100:2235-7. 